\title{
Effect of biopolymer stabilized silver nanoparticles on antioxidant genes from larvae of Anopheles Stephensi mosquito
}

\author{
Ondari Nyakundi Erick ${ }^{1,2 *}$, Nalini Padmanabhan $\mathrm{M}^{2}$, Maniga Nyabayo Josephat ${ }^{2,4}$ and Dickson Robert Opio $^{3}$ \\ ${ }^{1}$ Kisii University, Faculty of Pure and Applied Sciences, Department of Biological Sciences, P. O Box 408-40200, Kisii, Kenya \\ ${ }^{2}$ Kampala International University in Tanzania, Faculty of Medicine, Department of Medical Microbiology and Immunology P.O Box 9700 Dar-es-salam, Tanzania \\ ${ }^{3}$ Poompuhar College, Melaiyur 609 107, Sirkali Taluk, Nagapattinam District, India \\ ${ }^{4}$ Kampala International University, Western Campus, Faculty of Biomedical Sciences, Department of Medical Microbiology and Immunology, P. O Box 71 Bushenyi, Uganda
}

\begin{abstract}
It is now a fact that silver nano-particles (AgNPs) have many commercial applications wherein AgNPs formulations have exhibited potent insecticidal activity. Our previous research findings demonstrated that the biopolymer stabilized AgNPs cause death at the different developmental stages of $A$. stephensi. This study was undertaken to examine the toxic effects of biopolymer stabilized AgNPs on various antioxidant gene markers to shade light on mechanism behind death of sanguinivorous insects. The systemic effect analyses on biomarker enzymes and at gene level were characterized after exposure to various biopolymer stabilized AgNPs whereby a concentration of 5 ppm was used based on our previous studies. The AgNPs were shown to up-regulate the total protein levels significantly. The activities of antioxidant enzymes catalase and superoxide dismutase were significantly higher statistically whilst glutathione peroxidase was significantly lower which augmented well to the mRNA level expression profiles. The results indicate that the various biopolymer stabilized AgNPs induce up-regulation of the total protein levels as well as oxidative stress related machineries. These findings suggest that formation of reactive oxygen species via detoxification system may play a role in modulating host defense for the observed larval mortality and thus warrants microarray analyses to reveal the pathways involved for AgNPs formulation as the antioxidant gene responses in $A$. stephensi are highly diversified, in response to biotic and abiotic stressors. Knowledge on this will not only pave way for novel anti-mosquitol agents but as well offer screening methodology to curb $A$. stephensi management and incorporated for integrated pest management.
\end{abstract}

\begin{abstract}
Abbreviations: CAT: catalase, GPX: glutathione peroxidase, SOD: superoxide dismutase, CYT: cytoplasmic actin, FP: forward primer, RP: reverse primer, AgNPs: silver nanoparticles, ROS: reactive oxygen species

\section{Introduction}

Mosquitoes are the most notorious undesirable arthropods, with respect to transmission of malaria, dengue, filariasis and viral encephalitis [1]. Malaria is a complex disease afflicting human population. According to World Malaria Report 2016, the survey indexed that about 212 million people were new malarial cases and 429000 deaths globally. Malaria remains to be the most vital cause of morbidity and mortality in India and in many other tropical countries approximated at 2 to 3 million new cases arising every year, where $12 \%$ of malaria cases are due to Anopheles stephensi alone [2]. Based on these reports, A. stephensi, causative of malaria is given emphasis being the most prevalent species in India. It is devastating to note that despite continued efforts in search for effective malarial vaccine candidates, malaria holds a serious threat to humans. Thus, the only scheme to curb mosquito borne diseases significantly is to reduce mosquito population by deploying effective mosquito control strategies.
\end{abstract}

Recently, synthesized biogenic silver nanoparticles (AgNPs) are investigated as potential nanocides against mosquitoes [3, 4]. While there are many reports for mechanistic mode of action, responsible for bacterial death, invertebrate mortality mechanisms remain elusive. Bacteria mortality occurs via formation of reactive oxygen species (ROS), cell membrane damage, interaction with DNA, cell defensins, cytoplasmic disintegrations and mitochondrial malfunctions, which all together compromise physiological normalcy facilitating death. However, these observations have not been proven in mosquitoes, though reports in Drosophila points to copper starvation condition like which causes death [5]. Hence, the current work sort to elucidate the mode action of the bio-polymer stabilized AgNPs for the observed mortality as reported in our previous research [4]. The study analyzed antioxidant genes, which play essential role as defensins when the insect is exposed to oxidative stress via detoxification system which combats deleterious effects [6].

\section{Materials and methods}

\section{Collection of Anopheles stephensi larvae}

A. stephensi (I instar) were collected from Centre for Research in Medical Entomology (CRME-ICMR), Madurai and reared under laboratory conditions at $26 \pm 2^{\circ} \mathrm{C}$ with $18: 6 \mathrm{~h}$ (light: dark) photoperiod and $75-80 \%$ humidity. Larvae were fed with dog biscuit and baker's yeast in the ratio $3: 1$.

Correspondence to: Ondari Nyakundi Erick, Kisii University, Faculty of Pure and Applied Sciences, Department of Biological Sciences, P. O Box 408-40200, Kisii, Kenya, Tel: +254 710986 642; E-mail: drerickondarin@gmail.com

Key words: Anopheles stephensi, antioxidant genes, reactive oxygen species, biopolymer AgNPs.

Received: October 21, 2017; Accepted: November 17, 2017; Published: November 20, 2017 


\section{Preparation of homogenate}

Both treated and control (fourth instar and pupae) were pooled to eppendorff held on ice and homogenized and centrifuge (10,000 rpm, $4^{\circ} \mathrm{C}, 20 \mathrm{~min}$ ). The resulting supernatant was held on ice till use.

Total protein estimation: Protein estimation was carried according to the method of Lowry et al. (1951).

Glutathione peroxidase (GSH): GSH level was measured according to the method of Ellman, (1959). Briefly, to $1.5 \mathrm{ml}$ of tissue homogenate, $1 \mathrm{ml}$ of $10 \%$ TCA was added and centrifuged (11000 rpm, $4^{\circ} \mathrm{C}, 15 \mathrm{~min}$ ). To $0.5 \mathrm{ml}$ of supernatant, $2 \mathrm{ml}$ of $6 \mathrm{mM} \mathrm{DTNB}$ was added and total volume made to $3 \mathrm{ml}$ using $0.2 \mathrm{M}$ phosphate buffer $(\mathrm{pH} 8)$. Read OD at $412 \mathrm{~nm}$ and glutathione content was expressed in nmoles/ mg protein.

Superoxide dismutase (SOD): SOD level was measured according to the method of Ahmed et al. (2010). Briefly, to $0.1 \mathrm{ml}$ of tissue homogenate, $0.75 \mathrm{ml}$ of ethanol, $0.15 \mathrm{ml}$ of chilled chloroform was added and centrifuged ( $4000 \mathrm{rpm}, 4^{\circ} \mathrm{C}, 5 \mathrm{~min}$ ). To $0.5 \mathrm{ml}$ of supernatant, $0.5 \mathrm{ml}$ of $0.6 \mathrm{mM}$ EDTA, $1 \mathrm{ml}$ of $0.1 \mathrm{M}$ bicarbonate buffer ( $\mathrm{pH} 10.2)$ and $0.5 \mathrm{ml}$ of $1.3 \mathrm{mM}$ epinephrine were added. Read OD at $480 \mathrm{~nm}$, enzyme was expressed as units $/ \mathrm{min} / \mathrm{mg}$ protein.

Catalase (CAT): CAT level was measured according to the method of Ahmed et al. (2010). Briefly to $0.1 \mathrm{ml}$ of tissue homogenate, 1.2 $\mathrm{ml}$ of $50 \mathrm{mM}$ phosphate buffer $(\mathrm{pH} 7)$ and $1 \mathrm{ml}$ of $30 \mathrm{mM}$ hydrogen peroxide solution were added. Read OD at $570 \mathrm{~nm}$ for 3 mins at 15 secs, activity was expressed in $\mu \mathrm{M}$ of hydrogen peroxide decomposed/ $\mathrm{min} / \mathrm{mg}$ protein.

Statistical analysis: Each experiment was performed with three determinations using samples from different preparations. The difference in the levels of various biochemical parameters between treated and control larvae were tested for statistical significance using mean difference Student's $t$-test (SPSS Software package version 16). The acceptance level of statistical significance was $\mathrm{p}<0.05$ in all cases.

\section{Isolation of total RNA and CDNA synthesis}

Total RNA was isolated from A. stephensi exposed to TPAF, biogenic AgNPs, PEG-AgNPs, PVP-AgNPs, SDS-AgNPs and Tween 20-AgNPs and control using TRIzol Reagent (Ambian', Life Technology, USA) as per manufacturer's instructions. The total RNA quantity was determined by Nanodrop-2000C (Thermos Scientific, USA). The integrity of RNA was checked in formamide gel electrophoresis. About 1-2 $\mu \mathrm{g}$ of RNA was used for First strand cDNA synthesis using Qiagen Kit and the cDNA synthesized were quantified using Nanodrop-2000C.

\section{Amplification of antioxidant bio-marker enzyme genes}

Transcript accumulation of all antioxidant genes were studied by RT-PCR, using cDNA as template. PCR was performed using Emarald Amp GT PCR Master Mix (TaKaRa, Bio INC, Japan). The list of the primer sequence used are illustrated in Table 1 following the PCR conditions $\left(94^{\circ} \mathrm{C}\right.$ for $10 \mathrm{~min}, 94^{\circ} \mathrm{C}$ for $1 \mathrm{~min}, 60^{\circ} \mathrm{C}$ for $45 \mathrm{sec}, 72^{\circ} \mathrm{C}$ for $5 \mathrm{~min}, 35 \mathrm{cycles}$ ) for catalase, glutathione peroxidase and superoxide dismutase whereas cytoplasmic actin was kept as housekeeping gene. Primers were designed based on the mRNA partial conserved sequences using PRIMMER3 (http://primer3.ut.ee/), online software, following alignment using Geneious Pro software version R7, and synthesized by Eurofins, Genomics India PVT. Ltd., Bengaluru. The PCR products were resolved in $1 \%$ agarose gel, stained with $\mathrm{EtBr}$ and visualized in gel documentation unit (Syngene, USA).

\begin{tabular}{|c|l|}
\hline Gene & Primer sequence \\
\hline \multirow{2}{*}{ CAT } & $\begin{array}{l}\text { FP: 5'-CGT TCA CCT AAT CGA CGA GC-3' } \\
\text { RP: 5'-TCA AAG TAG CCG AAG GCA CC-3' }\end{array}$ \\
\hline \multirow{2}{*}{ GPX } & $\begin{array}{l}\text { FP: 5'-TTG ACT CGG GTG TGC TGT TC-3' } \\
\text { RP: 5'-ACT TGC TAC GAT CCA TCG GG-3' }\end{array}$ \\
\hline \multirow{2}{*}{ SOD } & $\begin{array}{l}\text { FP: 5'-TCT CGG CAA GAC CAA CCA TC-3' } \\
\text { RP: 5'-TCG AGA ACT CCA ATC ACG CC-3' }\end{array}$ \\
\hline \multirow{2}{*}{ CYT } & $\begin{array}{l}\text { FP: 5'-TGG AAG GTG GAA AGC GAG G-3' } \\
\text { RP: 5'-CGC ATG CAG AAG GAG ATC AC-3' }\end{array}$ \\
\hline
\end{tabular}

\section{Sequencing and alignment}

The PCR products were cleaned using QIAquick PCR purification kit (Qiagen) according to manufacturer's instructions. DNA sequencing was performed at BioServe, Hyderabad, using ABI Prism BigDye $^{\mathrm{TM}} \mathrm{v} 3.0$ reaction kit according to manufacturer's instructions using ABI 3730 sequence analyser (Applied Biosystems). Both forward and reverse sequences attained were aligned by BioEdit tool using pairwise alignment and cross checked by CodonCode Aligner version 4.2.7. BLAST search was done online in NCBI (http://www.ncbi.nlm.nih.gov).

\section{Expression profile using quantitative RT-PCR (qRT-PCR)}

qRT-PCR amplification was performed using a MX3005P thermocycler (Stratagene, Agilent Technologies) in $10 \mu \mathrm{l}$ reaction set-up. The PCR conditions were $\left(95^{\circ} \mathrm{C}\right.$ for $10 \mathrm{~min}, 95^{\circ} \mathrm{C}$ for $45 \mathrm{sec}, 60^{\circ} \mathrm{C}$ for $45 \mathrm{sec}$, $72^{\circ} \mathrm{C}$ for $\left.50 \mathrm{sec}, 45 \mathrm{cycles}\right)$. Reaction mix without reverse transcriptase served as negative control. The specificity of detection and efficiency of reverse transcriptase products and the internal control were determined by examining the quality of amplification, dissociation (melting curve) and standard curve using cDNA template. During each cycle, fluorescence accumulation resulting from DNA amplification was analyzed and converted into cycle threshold (Ct) using MxPro software (version1.0; Stratagene, Agilent Technologies). All qRT-PCR reactions were performed in two technical replicates. A. stephensi specific cytoplasmic actin gene served as control.

\section{Results and discussion}

\section{Antioxidant enzyme biomarker analysis}

It is clear that there was protein level increase by $(54.12 \%)$ in treated larvae $14.872 \mathrm{mg} / \mathrm{ml}$ against control $9.103 \mathrm{mg} / \mathrm{ml}$. Statistical t-test attained at 0.0102 (Figure1) was significant based on the threshold of $p<0.05$. Earlier studies have demonstrated that Hsp70 protein which is very sensitive and used as a useful indicator for adverse biological impact has been found to be expressed highly in treated organisms as compared to the control [6]. Ryter et al., have also revealed that p53 and p38 proteins which are known to induce DNA damage and apoptosis, are used as genotoxicity markers were found to be highly expressed during oxidative stress. Therefore, we demonstrate that the higher expression of the proteins observed in this study could be due to the expression of many proteins. The CAT and SOD anti-oxidant enzyme bio-markers were found to be expressed highly whilst GPX expression decreased in treated samples compared to control (Figure 2). Our findings are concomitant to earlier observations involving A. aegypti exposed to Bacillus thuringiensis (Bt)-based formulations wherein levels of total protein, acetyl cholinestrase, $\alpha$-carboxylestrase and alkaline phosphatases were significantly decreased while acid phosphatase activity augmented $[9,10]$. Also, it has been shown that damage of DNA, proteins and lipids which lead to programmed cell death are adverse effects of ROS formation [12]. Yilma et al. (2013) demonstrated that AgNPs stabilized by PVP revealed reduced levels of prototypic cytokines, tumor necrosis factor (TNF), interleukin (IL-6), 


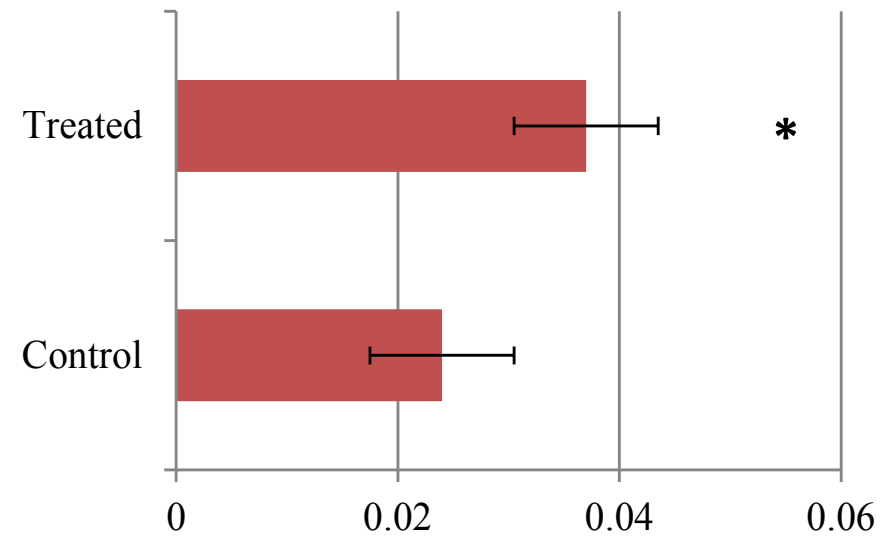

$\mathrm{mg}$ protein $/ \mathrm{ml}$ of homogenate

Figure 1. Effect of AgNPs on Total protein.

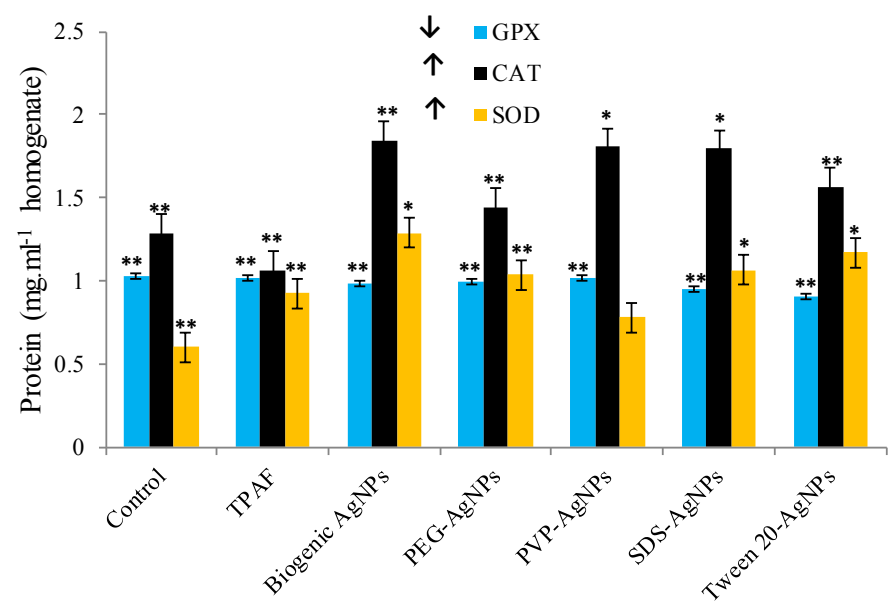

Figure 2. Antioxidant biomarker enzyme analysis. Values are expressed as mean $\pm \mathrm{SD}$ based on six replicates. ${ }^{* *} p<0.01,{ }^{*} p<0.05$

and chemokines. Also, these NPs have been found to up-regulate and down-regulate processes such as toll like receptors 2 (TLR 2), mRNA transcript in macrophages, nucleotide binding oligomerizationprotein 2 (NOD 2), CD40, CD80, CD86, IL-1 receptor associated kinase 3 (IRAK 3) and matrix metallopeptidase 9 (MMP 9) suggesting that AgNPs possessing PVP have wider applications which are yet to be realized apart from the current revelations. Also, Armstrong et al. (2013) have established in Drosophila that large uptake of AgNPs in association to membrane bound copper transport proteins cause sequestration of copper, thus creating a condition that resembles copper starvation resulting death.

\section{Relative mRNA expression pattern of antioxidant genes}

In general, formation of ROS induces accumulation of antioxidant genes, as defense mechanism to bring about normal physiological status of the organism [11]. It is clear from relative transcript patterns that there was a significant increase of CAT and SOD expression and GPX decrease (Figure 3) suggesting that oxidative stress is the primary mechanism for toxicity of Ag NPs in A. stephensi as earlier observed in D. melanogaster [9]. The current findings concur to biomarker enzyme analysis reported earlier whereby expression of antioxidant genes was induced in response to Plasmodium berghei midgut invasion [14]. This findings support our ealier published work where we revealed that ROS formation played a significant role on the observed larvae mortality.
The results revealed biogenic AgNPs as strong ROS inducers compared to biopolymer AgNPs and TPAF suggesting that biogenic AgNPs are strong ROS inducers than biopolymer AgNPs. However, it is interesting to note that these biopolymer AgNPs have the same impact as biogenic AgNPs. Hence, the findings show significant revelations that, bio-polymer AgNPs could be used as potential nanocides against Anopheles stephensi. Earlier, PVP stabilized AgNPs were found to upregulate/down-regulate various processes in Chlamydia trachomatis [16]. Various reports on antioxidant system defense, show that oxidative stress is the primary mechanism for toxicity of AgNPs, wherein accumulation of AgNPs in the nucleus is responsible for genomic damage and instability which consequently lead to DNA damage and apoptosis, facilitating mortality $[16,17]$.

\section{Conclusion}

Sanguinivorous insects including mosquitoes have developed a suite of antioxidant defense response in order to deal with to all forms of infection, feature which has enabled them to survive in different ecological niches. For example, Plasmodium infection, invokes ROS generation as a byproduct of mitochondrial respiration or as part of immune response to pathogens. On the other hand, resistance to pesticides including organochlorines, organophosphorous, carbamates and pyrethrin and pyrethroids based on their active ingredients they contain, have a potential to generate ROS which simultaneously has capacity to create oxidative stress in insects [18]. Phenolic compounds have been reported to generate ROS within insect tissues [19]. As stated earlier, exposure of AgNPs to bacteria causes mortality via i) uptake of free silver ions, ii) formation of ROS and iii) cell membrane damage through induction of pits, iv) interaction with enzyme cell defensins such as glutathione and glutathione disulfide, v) increase in DNA mutation frequencies, vi) cytoplasm contraction and disintegration,

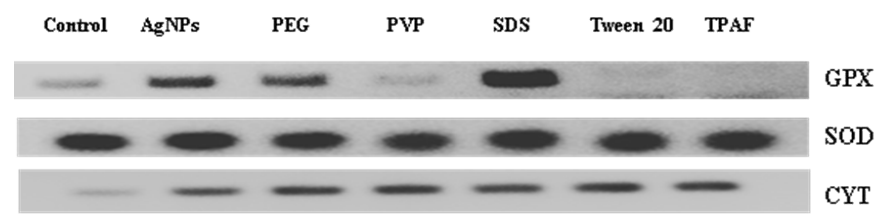

Figure 3. mRNA expression pattern of antioxidant genes by sqRT-PCR.

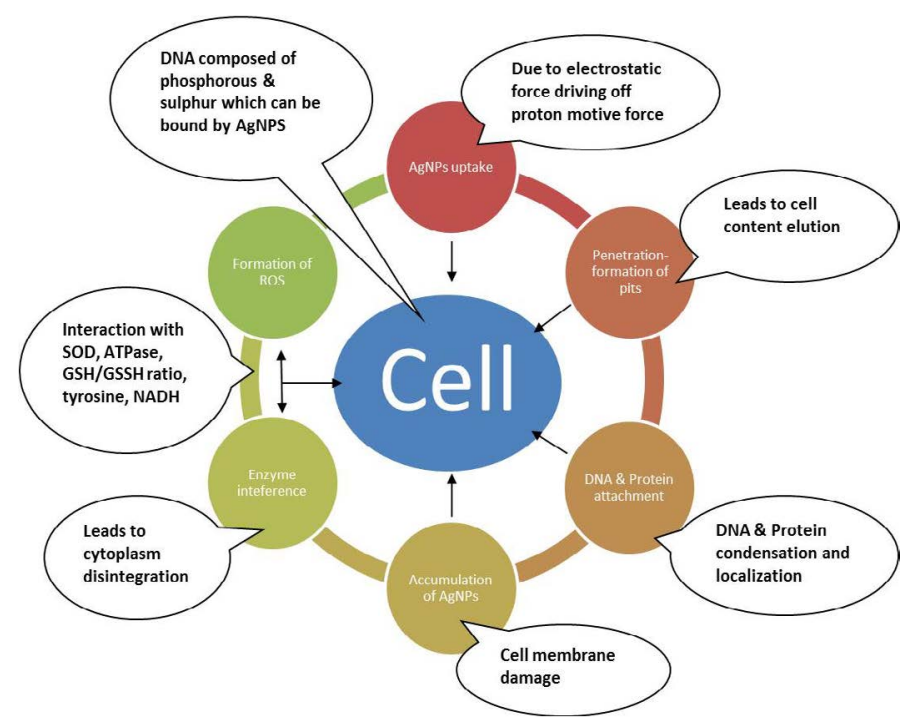

Figure 4. Various bacterial death mechanism(s) as reviewed in literature i.e. 1.AgNPs uptake 2. Formation of pits 3. Interaction with DNA and other proteins 4. Formation of ROS 5. Accumulation of AgNPs. 
vii) inhibition of replication, viii) formation of free radicals, which facilitate lipid membrane breakage and mitochondrial malfunction or DNA damage, as silver ions act as catalysts generating ROS in presence of dissolved oxygen during respiration as demonstrated in (Figure 4). Simultaneously, accumulation of ROS in mitochondria leads to release of Cytochrome $\mathrm{C}$ to cytosol, which triggers programmed cell death, and damage of biologically important macromolecules (DNA, proteins and lipids) [12]. Taken all together, the current findings support ROS generation as the evident mode of action responsive for the observed larval mortality. cDNA microaaray studies are needed to further point out the upregulation/down-regulation processes and their respective pathways, as these antioxidant gene responses in A. stephensi are highly diversified in response to both biotic and abiotic stressors. Knowledge on these molecules will serve as novel targets for anti-mosquito control strategies, as well as offer a screening methodology to curb parasite transmission in a wide range of other mosquito species.

\section{Acknowledgements}

The research was supported by Karpagam University through Dr. M. Nalini Padmanabhan, Department of Biotechnology. We also acknowledge Dr. R. Sathish and his entire research scholars, Department of Plant Genetic Engineering, Bharathiar University, Coimbatore, Tamil $\mathrm{Nadu}$, India for their immense help throughout the study.

\section{Competing interests}

All the authors declare that they don't any competing interests

\section{References}

1. Rueda LM (2008) Global diversity of mosquitoes (Insecta: Diptera: Culicidea) in freshwater. Hydrobiologia, 595: 477-487.

2. Gakhar SK, Richa S, Arvind S (2013) Population genetic structure of malaria vector Anopheles stephensi Liston (Diptera: Culicidae). Indian J Exp Bio 51: 273-279.

3. Sundaravadivelan C, Nalini MP, Sivaprasath P, Kishmu L (2013) Biosynthesized silver nanoparticles from Pedilanthus tithymaloides leaf extract with anti-developmental activity against larval instars of Aedes aegypti L (Diptera; Culicidae). Parasitol Res 112: 303-311.

4. Erick NO, Nalini MP (2015) Green chemistry focus on optimization of silver nanoparticles using response surface methodology (RSM) and mosquitocidal activity: Anopheles stephensi (Diptera: Culicidae). Spectrochim Acta A 149: 978-984.
5. Armstrong N, Ramamoorthy M, Lyon D, Jones K, Duttaroy A (2013) Mechanism of silver nanoparticles action on insect pigmentation reveals intervention of copper homeostasis. PLoS ONE 8: e53186. doi:10.1371/journal.pone.0053186.

6. Rajarapu SP, Mamidala P, Herms DA, Bonello P, Mittapalli O (2011) Antioxidant genes of the emerald ash borer (Agrilus planipennis): gene characterization and expression profiles. J Insect Physiol 57: 819-824.

7. Jones DT (1999) Protein secondary structure prediction based on position specific scoring matrices. J Mol Bio 292: 195-202.

8. Chaitanya RK, Sridevi P, Kumar KS, Mastan BS, Arun Kumar K, et al. (2014) Expression analysis of reactive oxygen species detoxifying enzyme genes in Anopheles stephensi during Plasmodium berghei midgut invasion. Asian Pac J Trop Med 680-684.

9. Ahamed M, Ryan P, Timothy JG, Mark N, Saber MH, et al. (2010) Silver nanoparticles induced heat shock protein 70 , oxidative stress and apoptosis in Drosophila melanogaster. Toxicol Appl Pharmacol 242: 263-269.

10. Koodalingam A, Mullainadhan P, Rajalakshmi A, Deepalakshmi R, Ammu M (2012) Effect of a Bt-based product (Vectobar) on esterases and phosphatases from larvae of the mosquito Aedes aegypti, Pesticide. Biochem Physiol 104: 267-272.

11. Nel A, Xia T, Mädler L, Li N (2006) Toxic potential of materials at the nanolevel. Science 311: 622-627. [Crossref]

12. Halliwell B (2006) Reactive species and antioxidants. Redox biology is a fundamental theme of aerobic life. Plant Physiol 141: 312-322. [Crossref]

13. Yilma AN, Singh SR, Dixit S, Dennis VA (2013) Anti-inflammatory effects of silverpolyvinyl pyrrolidone (Ag-PVP) nanoparticles in mouse macrophages infected with live Chlamydia trachomatis. Int J Nanomed 8: 2421-2432.

14. Tamura K, Dudley J, Nei M, Kumar S (2007) MEGA4: Molecular evolutionary genetics analysis (MEGA) software version 4.0. Mol Biol Evol 24: 1596-1599.

15. Molina-Cruz A, DeJong RJ, Charles B, Gupta L, Kumar S, et al. (2008) Reactive oxygen species modulate Anopheles gambiae immunity against bacteria and Plasmodium. $J$ Biol Chem 283: 3217-3223.

16. Ryter SW, Kim HP, Hoetzel A, Park JW, Nakahira K, et al. (2007) Mechanisms of cell death in oxidative stress. Antioxid Redox Signal 9: 49-89. [Crossref]

17. Asharani PV, Lian Wu Y, Gong Z, Valiyaveettil S (2008) Toxicity of silver nanoparticles in zebrafish models. Nanotechnology 19: 255102. [Crossref]

18. Alout H, Ndam NT, Sandeu MM, Djégbe I, Chandre F, et al. (2013) Insecticide resistance alleles affect vector competence of Anopheles gambiae, s.s. for Plasmodium falciparum field isolates. PLOS ONE 8: e63849.

19. Krishnan N, Kodrík D (2006) Antioxidant enzymes in Spodoptera littoralis (Boisduval): are they enhanced to protect gut tissues during oxidative stress? J Insect Physiol 52: 11-20. [Crossref]

Copyright: (C2017 Erick ON. This is an open-access article distributed under the terms of the Creative Commons Attribution License, which permits unrestricted use, distribution, and reproduction in any medium, provided the original author and source are credited. 